\title{
Original Research \\ Separation of Lactic Acid Solutions from Whey Fermentation Broth Using Zirconium (IV) Hydrous Oxide Dynamically Formed Membranes
}

\author{
Brygida Wojtyniak ${ }^{1 *}$, Daniela Szaniawska ${ }^{2}$ \\ 'Faculty of Chemical Technology and Engineering, West Pomeranian University of Technology, \\ Piastow 42, 70-065 Szczecin, Poland \\ ${ }^{2}$ Maritime University of Szczecin, H. Poboznego 11, 70-507 Szczecin, Poland
}

Received: 6 March 2014

Accepted: 23 September 2014

\begin{abstract}
We investigated separation of lactic acid solutions from model fermentation broth using a dynamically formed ultrafiltration membrane. The model fermentation broth was prepared from whey and Lactobacillus acidophilus bacteria. The research evaluates the influence of select lactic acid bacteria on fermentation product quality. The specific objectives of the study were to evaluate the performance of an ultrafiltration membrane consisting of zirconium oxide stainless steel (ZOSS) on lactic acid purification. We measured the effects of transmembrane pressure, cross-flow velocity, and initial bacteria concentration of the feed stream on permeate flux and lactic acid recovery. Experiments to test the lactic acid recovery were conducted at two pressure levels (1.0 and 2.0 MPa), one bacteria concentration $\left(1 \mathrm{~g} / \mathrm{dm}^{3}\right)$, and three values for the cross flow velocity $(0.5 \mathrm{~m} / \mathrm{s}, 1 \mathrm{~m} / \mathrm{s}$, and $2.6 \mathrm{~m} / \mathrm{s})$. We also evaluated the influence of select lactic acid bacteria on fermentation product quality.
\end{abstract}

Keywords: ultrafiltration, hydrous oxide dynamically formed membranes, whey, lactic acid, Lactobacillus acidophilus

\section{Introduction}

In response to environmental concerns, recent research has mainly focused on membrane filtration technologies, which provide promising new opportunities for large-scale product separation. Here we present the results of a membrane separation technique for whey processing and the production of whey-based functional compounds. Briefly, cheese whey is a by-product that can be used to produce lactic acid. Processes for lactic acid production typically include two key stages of fermentation and product recovery.

The manufacturing of cheese produces large volumes of whey as waste. Whey, the liquid residue of cheese and

*e-mail: brygida.wojtyniak@gmail.com casein production, is one of the biggest reservoirs of food protein remaining largely outside of human consumption channels. Global whey production is more than 160 million tons per year [1,2]. Lactic acid is a versatile chemical used in food and chemical industries. The high operating costs of traditional processes for lactic acid production by lactose fermentation come from the separations steps needed to meet quality requirements for food-grade lactic acid. Membrane technologies are separation methods used in agro-industries to concentrate and/or purify different product streams. The dairy industry represents one of the greatest application areas of membrane separation technologies. Four basic types of membranes present potential applications for the dairy industry, e.g. reverse osmosis (RO), nanofiltration (NF), ultrafiltration (UF), and microfiltration 
(MF) [2-4]. When used in milk processing, UF produces retentates containing proteins, fat, and colloidal materials in higher proportions than those found in untreated milk, and permeates consisting of water, minerals, lactose, non-protein nitrogen compounds, and water-soluble vitamins. The major advantages of ultrafiltration over competing separation technologies are high product throughput, the relative ease of scale-up, and the ease of equipment cleaning and sanitizing [5].

Lactic acid can be produced by fermentation of sugarcontaining substrates such as cheese whey using Lactobacillus acidophilus. A successful lactic acid recovery approach utilizing a filtration unit in continuous fermentation in a recycled reactor results in lactic acid removal from the while cells, protein, and lactose, which are separated and subsequently returned to the fermentor. A membrane bioreactor integrating the processes of fermentation and separation could present valuable advantages with respect to increased lactic acid production. This method is expected to reduce product inhibition, reuse the unconverted substrate, obtain high cell density cultures, and decrease load on the next separation process $[4,6]$.

Lactobacillus acidophilus are thermophilic and acidophilic bacteria that can grow under conditions that are inhibitive for most contaminant microorganisms. Batch fermentation studies with Lactobacillus acidophilus revealed a $\mathrm{pH}$ of 5.6 for lactic acid production whereas $\mathrm{pH}=6.5$ was found to be optimal for bacteria growth. Higher substrate (lactose) concentrations resulted in longer fermentation times and reduced specific productivity. Since it contains mostly lactose, it can be a good source for lactic acid production $[7,8]$.

We report an experimental study of the possibility of applying inorganic membranes in continuous systems for lactic acid production from whole whey. The first part of this study consists of identifying and selecting proper input data for fermentation. The second part presents ultrafiltration results of model whey solution with the goal of analyzing the effects of several operating parameters on permeability and selectivity of investigated membrane: transmembrane pressure, cross-flow velocity, and bacteria concentration.

\section{Theory}

\section{Basic Operating Principles of Ultrafiltration Membranes}

There are two main issues in an ultrafiltration process: production rate and selectivity. The production rate is quantified in terms of the permeating flux $\left(J_{v}\right)$, defined as the permeation rate per unit membrane surface area $[9,10]$ :

$$
J_{v}=\frac{1}{A} \cdot \frac{d V}{d t}
$$

The permeate flux $\left(J_{v}\right)$ decreases with increasing feed concentration; this is due to the build-up of a polarization layer which occurs earlier when the feed concentration is high. Once concentration polarization is in effect, fouling can proceed by several means: adsorption, pore blocking, cake layer formation, and depth fouling.

The permeate flux is influenced by the following operating conditions [10]:

- Feed concentration $\left(C_{f}\right)$ - feed concentration can affect the performance of the UF in two ways: through the process flux (permeate flow rate per unit area) and with respect to the transmission of the permeable molecules. The film theory model states that the flux decreases exponentially with increasing feed concentration. This relationship should hold irrespective of the type of flow, the degree of turbulence, or temperature.

- Temperature $(T)$ - higher temperatures lead to a higher flux both in the pressure controlled and mass transfercontrolled regimes. This assumes that there are no simultaneously occurring unusual effects. For instance, higher temperatures may result in precipitation of insoluble salts that can promote fouling of the membrane. In the pressure-controlled regime, the effect of temperature on flux is due to its effect on fluid density and viscosity.

- Cross-flow velocity $(u)$ - higher fluid velocities increase the mass transfer coefficient and thus the permeation flux.

- Transmembrane pressure $(\Delta P)$ - is the driving force for the pressure-driven membrane process. The permeate flux through a membrane is observed to be proportional to the applied pressure across the membrane surface due to increased fouling and compaction.

- Time $(t)$ - one of the problems during ultrafiltration (UF) is the marked decline of permeate flux with time. This is mostly attributed to the phenomenon of concentration polarization and the associated fouling problem. The separation of process liquid and solute taking place at the membrane during ultrafiltration gives rise to an increase in solute concentration close to the membrane surface. This effect is called concentration polarization and takes place within the boundary layer generated by the applied cross-flow. Permeate flux is also affected by membrane fouling: in constant transmembrane pressure ultrafiltration processes the permeate flux decreases with time due to fouling. Fouling is attributed to many factors, one being sludge particle deposition, (i.e., adhesion of macromolecules to the membrane surface and/or pore clogging by small molecules). Cake layer formation by sludge particle deposition is the most common reason for the flux decline. Fouling will not be observed when the flux is maintained below "critical flux," but beyond this critical value the particles start to deposit on membrane surface as a cake layer. The cake layer is readily removable from the membrane by physical washing protocol. On the other hand, internal fouling caused by adsorption of dissolved matter into the membrane pore, and pore blocking are considered irreversible, and is generally removed by chemical cleaning. In addition, formation of a gel layer on a membrane surface is often irreversible, although it is theoretically reversible. Irreversibility is attributable to the formation of the cake layer and resulting reduction in membrane lifetime. 


$$
J_{v}=\frac{\Delta P}{\mu R_{T}}
$$

Equations (1) and (2) could be rewritten as:

$$
\frac{1}{A} \cdot \frac{d V}{d t}=\frac{\Delta P}{\mu R_{T}}
$$

...where $R_{T}$ is the total hydraulic resistance of the membrane and can be represented as the summation of the following two components: resistance of the clean membrane $\left(R_{m}\right)$ and overall fouling resistance $\left(R_{f}\right)$ which, itself, is considered an additional resistance resulting from adsorption, concentration polarization, and solute and particle deposition by convection.

$$
\frac{1}{A} \cdot \frac{d V}{d t}=\frac{\Delta P}{\mu\left(R_{m}+R_{f}\right)}
$$

Most membrane manufacturers use the MWCO (molecular weight cut-off) to specify the solute retention characteristics of ultrafiltration membranes. The retention of a solute by a membrane depends primarily on the solute: to pore diameter ratio. It is also strongly dependent on the solute shape, charge, compressibility, membrane interactions (which depend on solution conditions), and operating parameters (such as cross-flow velocity and transmembrane pressure) [11]. Membrane selectivity is described by the rejection coefficient $(R)$. Rejection $(R)$ of ash, protein, lactose, and fat is given by Eq. (2).

$$
R=1-\frac{C_{p}}{C_{r}}
$$

...where $C_{p}$ and $C_{r}$ represent the lactic acid concentration in the permeate and retentate, respectively $[10,11]$.

\section{Experimental}

\section{Materials and Methods}

\section{Model Whey Solution}

Model whey solution was prepared by dissolving $77.1 \mathrm{~g}$ of whey from bovine milk powder (Sigma Aldrich) into $20 \mathrm{dm}^{3}$ of deionized water (DI) and stirring for $5 \mathrm{~min}$. at ambient temperature. The composition of whey powder was $27 \%$ protein (Biuret) and $65 \%$ lactose (nitrogen $2 \%$, moisture $4.4 \%$ ).

\section{Microorganism and Culture Conditions}

Lactobacillus acidophilus (Biolacta, Olsztyn, Poland) was used for the lactic acid fermentation in this study. The amount of $1.0 \mathrm{~g} / \mathrm{dm}^{3}$ of Lactobacillus acidophilus was added to the whey solution and subjected to fermentation for $13 \mathrm{~h}$. The bacteria were cultured in Ringer's medium. The whey was supplemented with components of broth, consisting of $10 \mathrm{~g}$ of yeast extract, $0.5 \mathrm{~g}$ of $\mathrm{NH}_{4} \mathrm{NO}_{3}$, and $5 \mathrm{~cm}^{3}$ of Tween 80 (polysorbit-80) per liter of distilled water.

\section{Chemical Cleaning Agent}

Before and between each experiment a chemical cleaning and sterilizing procedure was performed. The chemical cleaning agent used was: neoseptal D (Dr. Weigert). The stock chemical solution was prepared fresh by dissolving the chemical in deionized (DI) water. Additionally, the entire workstation was sterilized with UV light. This method of sterilization creates an ideal environment for the fermentation process by reducing the probability of contamination.

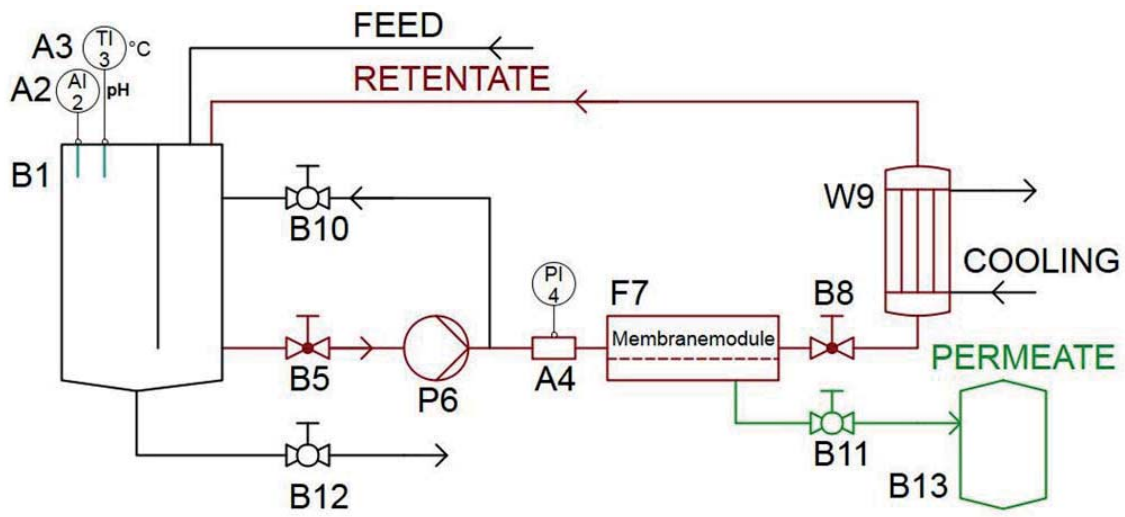

\begin{tabular}{|l|l|}
\hline B1 & Feeding tank \\
\hline A2 & pH electrode \\
\hline A3 & Temperature meter \\
\hline A4 & Pressure gauge \\
\hline B5 & Low-pressure valve \\
\hline P6 & Recirculation pump \\
\hline F7 & Membrane module \\
\hline
\end{tabular}

\begin{tabular}{|c|l|}
\hline B8 & High-pressure valve \\
\hline W9 & Heat exchanger \\
\hline B10 & Side valver \\
\hline B11 & Outlet valve \\
\hline B12 & Outlet valve \\
\hline B13 & Product tank \\
\hline
\end{tabular}

Fig. 1. Schematic diagram of the ultrafiltration membrane separation system. 


\section{Zirconium (IV) Hydrous Oxide Dynamically Formed Membranes UF Tests}

Filtration tests were performed using an UF pilot plant depicted schematically in Fig. 1. The ultrafiltration membrane used was zirconium (IV) hydrous oxide dynamically formed on a titanium microfiltration membrane, which was permanently attached to the inner surface of a porous sintered stainless steel tube (ZOSS-zirconium oxide stainless steel). The active surface area of the membrane was $0.029 \mathrm{~m}^{2}$.

The fermentation took place in a feed tank with separation plate, which had a volume of $20 \mathrm{dm}^{3}$. The tank temperature was monitored and controlled. The UF tests of model whey solution in the feed tank were performed with recirculation of the retentate. The retentate was recycled using the membrane module and returned to the feed tank through the pump and heat exchanger as shown in Fig. 1. The permeate was collected in a vessel after filtration. During the experiments temperature and $\mathrm{pH}$ were kept constant at $\mathrm{T}=37^{\circ} \mathrm{C}$ and $\mathrm{pH}=5.6$. The trans-membrane pressure and the cross-flow feed velocity were adjusted by a manual valve and pump con-

a)

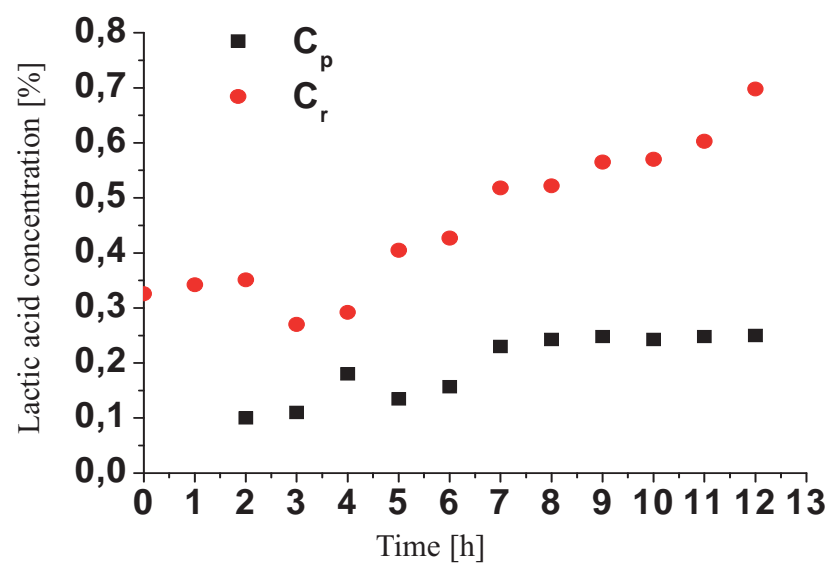

c)

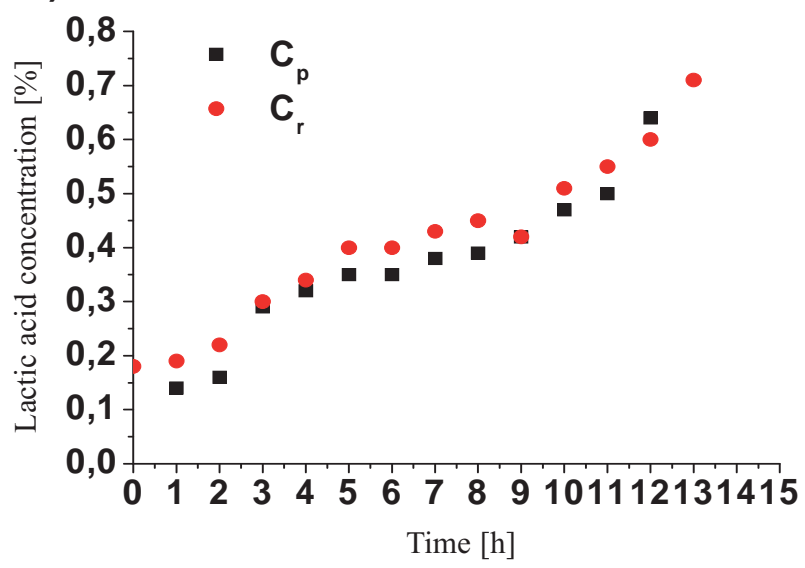

troller. The pressure was measured by a standard pressure gauge.

The cross-flow feed velocity was calculated from the flow rate and the area of the membrane channel. Values of the cross flow velocity used in the experiments were $u_{1}=0.5$ $\mathrm{m} / \mathrm{s}, \mathrm{u}_{2}=1.0 \mathrm{~m} / \mathrm{s}$, and $\mathrm{u}_{3}=2.6 \mathrm{~m} / \mathrm{s}$. Different trans-membrane pressures, ranging between 1.0 and $2.6 \mathrm{MPa}$, were tested and $C_{b}=1.0 \mathrm{~g} / \mathrm{dm}^{3}$ concentration of bacteria was used. Samples were taken every $60 \mathrm{~min}$ during the $13 \mathrm{~h}$ run. Each fermentation test lasted $14 \mathrm{~h}$.

Analysis

The physicochemical analysis of the produced lactic acid solutions were evaluated every hour when a sample was taken. The lactic acid and lactose concentrations were measured by titration with $0.25 \mathrm{M} \mathrm{NaOH}$, expressed in terms of milliliters of $\mathrm{NaOH}$, and by HPLC using an ion exclusion column (NucleogelR Ion 300 0A, MachereyNagel) with detection of the refractive index, applying techniques and methods included in the Polish Standards [12]. Cell number was determined by the pour plate counting method on MRS agar.

b)

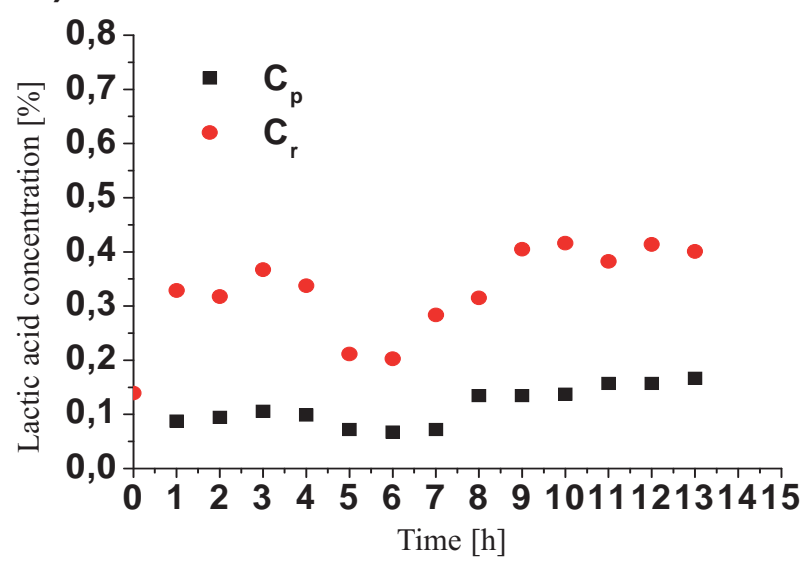

d)

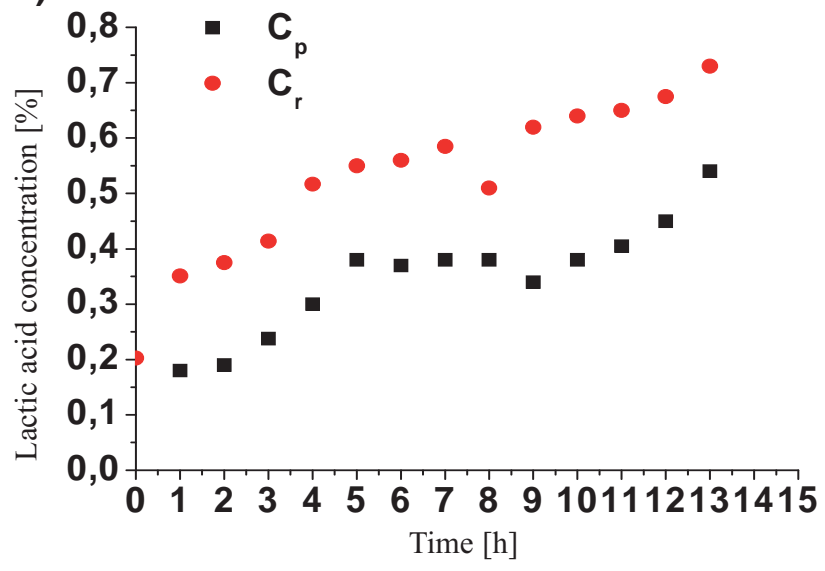

Fig. 2. Effect of operation parameters on the lactic acid concentration in the permeate $\left(C_{p}\right)$ (square symbols) and retentate $\left(C_{r}\right)$ (circle symbols) for the constant $C_{b}$ of $1.0 \mathrm{~g} / \mathrm{dm}^{3}$, a) $\left.\left.\Delta P=2.0 \mathrm{MPa}, \mathrm{u}_{2}=1.0 \mathrm{~m} / \mathrm{s}, \mathrm{b}\right) \Delta P=2.0 \mathrm{MPa}, \mathrm{u}_{3}=2.6 \mathrm{~m} / \mathrm{s}, \mathrm{c}\right) \Delta P=1.0 \mathrm{MPa}, \mathrm{u}_{1}=0.5$ $\mathrm{m} / \mathrm{s}$; and d) $\Delta P=1.0 \mathrm{MPa}, \mathrm{u}_{3}=2.6 \mathrm{~m} / \mathrm{s}$. 


\section{Results and Discussion}

\section{Effects of Ultrafiltration Operating Parameters on the Lactic Acid Concentration}

Fig. 2 illustrates a comparison of fermentation times with yeast extract, $\mathrm{NH}_{4} \mathrm{NO}_{3}$, and Tween 80 supplements. The starting concentration of lactose was constant, $C_{L}=$ $0.25 \%$. In this study, the lactic acid was produced in a feed tank. The model whey solution inoculated with Lactobacillus acidophilus was filtered by an ultrafiltration membrane.

The effects of supplementing the whey solutions with yeast extract and $\mathrm{NH}_{4} \mathrm{NO}_{3}$ as well as transmembrane pressure and cross-flow velocity were tested. It was found that these supplements were important for efficient fermentation by Lactobacillus acidophilus. The whey was supplemented with $10 \mathrm{~g}$ of yeast extract, $0.5 \mathrm{~g}$ of $\mathrm{NH}_{4} \mathrm{NO}_{3}$, and 5 $\mathrm{cm}^{3}$ of Tween 80 per litre; the bacteria concentration was 1 g/dm ${ }^{3}$. Fig. 2 presents results for the different feed velocities and pressures.

The experiments show that concentrations of lactic acid, in both permeate and retentate, increase with fermentation time.

The highest lactic acid concentration in permeate was attained at the low cross-flow velocity, $\mathrm{u}=0.5 \mathrm{~m} / \mathrm{s}$ and low trans-membrane pressure, $\Delta P=1.0 \mathrm{MPa}$ (Fig. 2c). Retentate lactic acid concentration tended to the reduction of value. This means that the fermentation of lactose to lactic acid works at $12 \mathrm{~h}$, which can be seen in the increase in lactic acid concentration in the permeate.

On the other hand, the higher transmembrane pressure or higher cross-flow velocity hinder fermentation performance. There are many approaches described in the literature for estimating the relevant membrane parameters. Most of those approaches are limited to low pressure and unstirred batch cells. Since bacterial cells significantly affect the course of fermentation in the reactor with a membrane, there are two important effects. Firstly, increases in

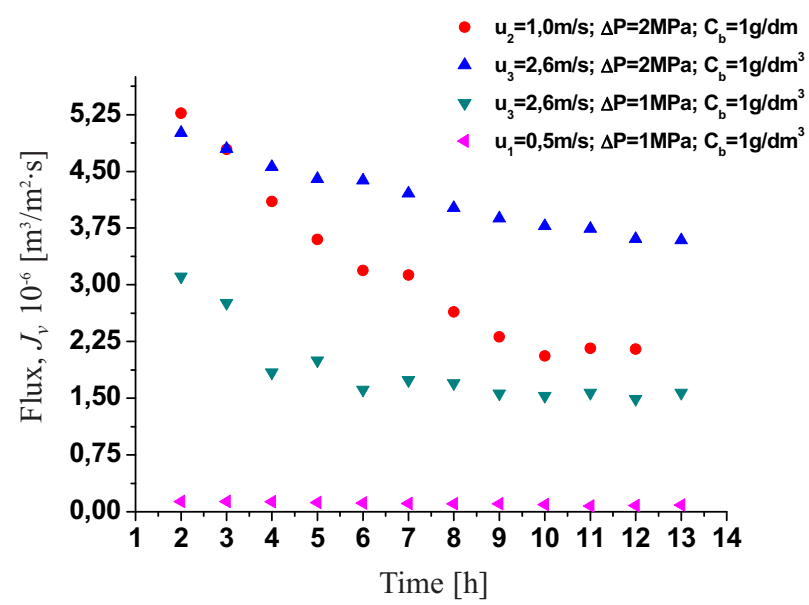

Fig. 3. Permeate flux $\left(J_{v}\right)$ obtained in the clarification of lactic acid fermentation broths by ultrafiltration zirconium (IV) hydrous oxide dynamically formed membrane and Lactobacillus acidophilus.

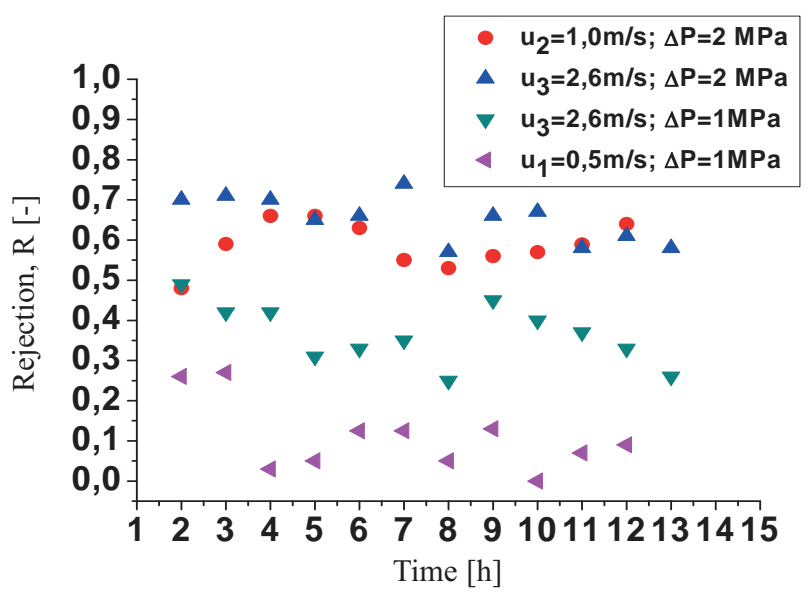

Fig. 4. Effect of cross-flow velocity and transmembrane pressure on lactic acid rejection coefficient (R) during $13 \mathrm{~h}$ tests; Lactobacillus acidophilus $C_{b}=1.0 \mathrm{~g} / \mathrm{dm}^{3}$ and supplements: $10 \mathrm{~g}$ of yeast extract, $0.5 \mathrm{~g}$ of $\mathrm{NH}_{4} \mathrm{NO}_{3}$, and $5 \mathrm{~cm}^{3}$ of Tween 80 per litre.

the contact time between the bacteria and the substrate produce higher conversion rates. Secondly, the lactic acid that is produced becomes increasingly concentrated. These results are in accord with published data in the literature [13].

Analysis of the Quality of Permeate Separated from the Fermentor Integrated with the Membrane Module and Hydrous Oxide Dynamically Formed Membranes

The effects of the operating parameters on the permeability $\left(J_{v}\right)$ and selectivity $(R)$ of the ZOSS membrane in the ultrafiltration of model whey solutions are presented in Figs. 3 and 4.

Observed variations in permeation flux through the UF membrane for different operating pressures and velocities are presented in Fig. 3. The experimentally obtained flux values are shown in Fig. 3 as well. It is seen that flux decreases as fouling (gel layer) grows over time. Hydrodynamics play an important role in this behaviour: permeate flux declined during the first 6 hours (except for the $\Delta P=1.0 \mathrm{MPa} ; \mathrm{u}_{1}=0.5 \mathrm{~m} / \mathrm{s}$ and $\mathrm{u}_{2}=1.0 \mathrm{~m} / \mathrm{s}$ ), slowed down gradually during the period of 6 to 8 hours, and after this period, flux was constant until it reached the end concentration process. As observed, at $\Delta P=2.0 \mathrm{MPa}$ and the cross flow velocity variation of $J_{v}$ can be divided into two stages. In the early stage of whey fermentation using UF, adsorption fouling is probably the primary mechanism of flux decline. In the second stage, the accumulation of particles during the run and the concentration polarization phenomenon may lead to the formation of a cake layer onto the membrane surface. When the solute flux driven toward the membrane by convection is compensated by the back transport of the solute away from the membrane, a constant cake layer thickness is reached, which is followed by a nearly constant permeate flux. This is because higher cross-flow velocities prevent the gel layer from growing rapidly. 
A closer look reveals that at higher operating pressure and velocity, the initial flux is also higher than the initial flux at lower velocity due to the increased driving force, but the flux eventually flattens out to the same steady-state value.The rejection characteristic also shows an interesting trend (Fig. 4). As illustrated in Fig. 4, while the rejections of lactic acid increased with increasing cross-flow velocity, for cross-flow velocity $0.5 \mathrm{~m} / \mathrm{s}$ it is observed that the rejections of lactic acid have an important gradual decrease. The rejection attained a stable value at $2.6 \mathrm{~m} / \mathrm{s}$ velocity. Higher transmembrane pressures and higher velocities lead to an increase of the rejection coefficients. Also, the growth rate of the fouling layer was reduced and the concentration polarization in the boundary layer was reduced as well.

At decreased $\Delta P$ pressure, membrane pores are blocked and a polarization layer forms on the surface. This phenomenon could be explained by the accumulation of lactic acid and cells as operating time extended. Fig. 4 indicates the effect of applied pressure on permeate flux decay. When permeate flux declined, rejections increased due to the developing secondary membrane on the surface and within the pores of the membrane. Optimal permeability was observed at high pressure, which explains the importance of diffusion transport. Process pressure $(\Delta P=1.0 \mathrm{MPa})$ seemed to be of great interest from an efficiency standpoint.

\section{Fouling Analysis}

Experimental fouling resistance was determined from experimental permeate flux by using Eq. (3). The values of $R_{f}$ could be calculated by the definition introduced at Theory Section: $R_{f}=\frac{\Delta p}{J_{V} \cdot \mu}-R_{m}$. Membrane resistance $R_{m}$ was determined by performing a clean water flux $\left(J_{w}=4.8 \cdot 10^{-3} \mathrm{~m}^{3} \cdot \mathrm{m}^{-2} \cdot \mathrm{s}^{-1}\right)$ on a clean membrane and was esteemed as $R_{m}=5.20 \cdot 10^{5} \mathrm{~m}^{-1}$. Typical fouling results from a benchmark fouling experiment are present permeate flux $\left(J_{v}\right)$ and fouling resistance versus time in Fig. 5.

The line with circle symbols in Fig. 5 connects the starting point of the fouling from $2 \mathrm{~h}$ to $12 \mathrm{~h}$. The high increase

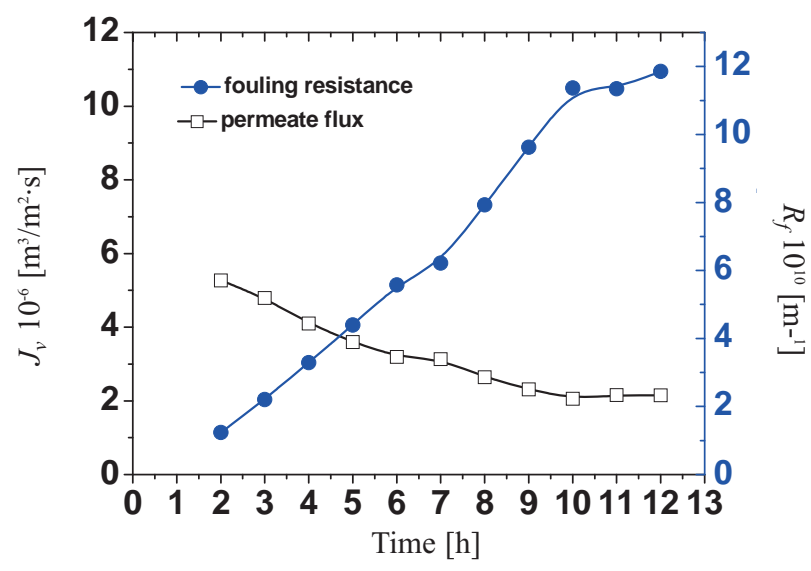

Fig. 5. Effect of time on permeate flux $\left(J_{v}\right)$ and fouling resistance $\left(R_{f}\right)$ for $\Delta P=2.0 \mathrm{MPa} ; \mathrm{u}_{3}=1.0 \mathrm{~m} / \mathrm{s} ; C_{b}=1.0 \mathrm{~g} / \mathrm{dm}^{3}$. in resistance is due to the cells fouling the membrane. Also, permeate flux decreased at a pressure of $2.0 \mathrm{MPa}$ and crossflow velocity of $1.0 \mathrm{~m} / \mathrm{h}$. These results imply that ZOSS membrane was fouled during the fermentation process. The extent of fouling depends on process factors such as pressure or velocity. Typically, the transmembrane pressure (TMP) difference is fixed, and the flux is allowed to decline as the membrane fouls while the resistance to mass transfer increases [14]. However, as flux varies, so too does the rate at which substances are brought to the membrane surface, so the observed fouling behavior is not solely the result of membrane/foulant interactions. In most cases permeate flux is considered a key design parameter for membrane systems and reflects membrane productivity. The two factors that led to deterioration of the flux rate were fouling and concentration polarization.

\section{Conclusions}

The ultrafiltration ZOSS membrane used in this study was able to most effectively separate lactic acid from model whey fermentation broth at operating parameters $\mathrm{u}_{2}=2.6 \mathrm{~m} / \mathrm{s}$ and $\Delta P=1.0 \mathrm{MPa}$. It was found that lactic acid rejection is adversely affected by the decrease of crossflow velocity and low transmembrane pressure $(\Delta P)$. A transmembrane pressure of $1.0 \mathrm{MPa}$ and a low cross flow velocity of $0.5 \mathrm{~m} / \mathrm{s}$ increased the concentration of lactic acid but hindered the hydrodynamic operating conditions of the membrane. The trans-membrane pressure also had an important effect on fouling, while a lower transmembrane pressure reduces the concentration of cells deposition in the membrane. However, a reduced pressure also reduced driving force. Constant flux, where the permeate flux is fixed and the TMP difference varies, minimized such variations in the hydrodynamic conditions at the membrane surface, but constant TMP difference experiments dominate the fouling literature because they are more straightforward to execute than constant flux experiments.

From calculations using the parameters obtained we conclude time-dependent fouling caused the main resistance to permeate flux during the ultrafiltration of a model broth. The description of both lactic acid rejection and the membrane fouling can be used to inform and optimize lactic acid from fermentation broth UF separation processes. From our results it can be concluded that it is beneficial to remove cells by ultrafiltration prior to NF.

The presented findings will be useful in selecting optimal parameters in future research with whey and lactic acid bacteria. UF retentate purification processes are optimized by including a nanofiltration (NF) step. Compared with the conventional process, UF and NF have the advantage of allowing for higher lactic acid recovery. This hybrid process includes two basic steps:

1. An ultrafiltration concentration stage two maximize the concentration of high molecular weight solute in the retentate

2. Nanofiltration to purify the permeate from UF 
It will be interesting to see how future investigations of integrated, hybrid configurations (UF and NF) will add to our understanding of membrane processes.

\section{Acknowledgements}

This work was partially financially supported by the Polish Ministry of Science and Higher Education (grant No. 3S/IIT/14).

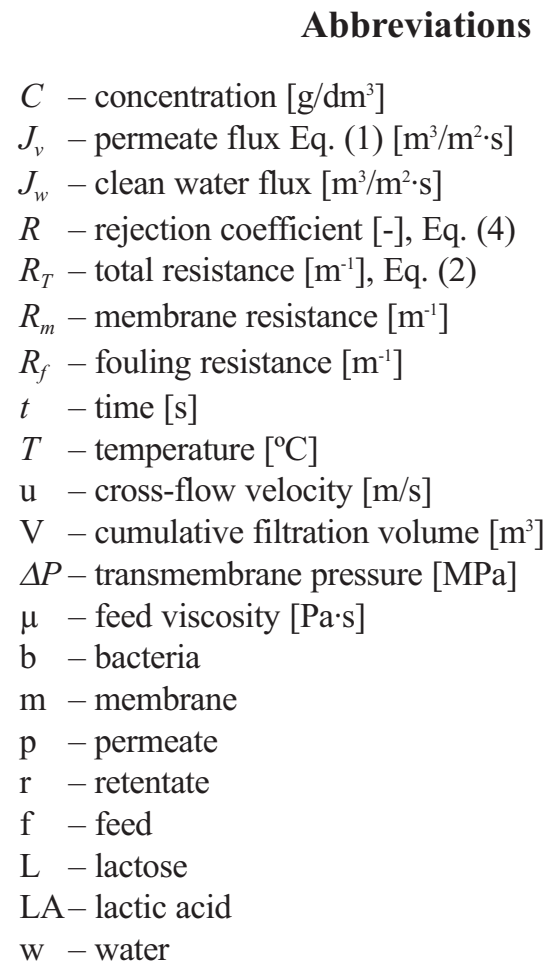

\section{References}

1. World Cheese Sale Beat Whey Sales in Volume not Growth, Market Matters. Hoogwegt Horizons, 8, (1), 9 January 2012.
2. SPALATELU C. Biotechnological valorization of whey. Innovative Romanian Food Biotechnology, 10, March, 2012.

3. Dairy Processing Handbook, Edition 2, Hardback, Dec 2003.

4. CUARTAS-URIBE B., ALCAINA-MIRANDA M.I., SORIANO-COSTA E., MENDOZA-ROCA J.A., IBORRA-CLAR M.I., LORA-GARCIA J. A study of the separation of lactose from whey ultrafiltration permeate using nanofiltration, Desalination 241, 244, 2009.

5. Handbook of Membrane Separations, Chemical, Pharmaceutical, Food, and Biotechnological Applications, Ranja Ghosh, Chapter 18. Ultrafiltration-Based Protein Bioseparation, CRC Press 2008.

6. YUWONO S.D., KOKUGAN T. Lactic acid production from fresh cassava roots using single-stage membrane bioreactor. Modern Applied Science, 6, (1), January 2012.

7. OSTASIEWICH A., ZAREBA D. The influence of lactobacillus acidophilus la-5 probiotic strain of lactic acid bacteria on rye bread quality. Zywnosc, Nauka. Technologia. Jakosc, 5, (60), 189, 2008 [In Polish].

8. ZAHEER A., YANPING W., QIAOLING CH., IMRAN M. Lactobacillus acidophilus bacteriocin, from production to their application: An overview, African Journal of Biotechnology, 9, (20), 2843, 17 May 2010.

9. ALKHATIM H.S., ALCAINA M.I., SORIANO E., IBORRA M.I., LORA J., ARNAL J. Treatment of whey effluents from dairy industries by nanofiltration membrane. Desolination 119, 177, 1997.

10. BAKER R. W. Membrane Technology and Applications. $2^{\text {nd }}$ edition, John Wiley \& Sons Ltd, West Sussex, 2004.

11. CHERYAN M. Ultrafiltration and Microfiltration Handbook. Technomic publishing, company, Inc. Lancaster, 1998.

12. PN-83/A-86341 The milk and dairy preserves. Milk drinks ferment [In Polish].

13. MATIJEVIC B., LISAK K. Impact of enzymatic hydrolyzed lactose in fermentation and growth of probiotic bacteria in whey. Mljekarstvo 61, (2), 154, 2011.

14. GONZALEZ M., ALVAREZ S., RIERA F., ALVAREZ R. Lactic acid recovery from whey ultrafiltrate fermentation broths and artificial solutions by nanofiltration. Desalination 228, 84, 2008. 
